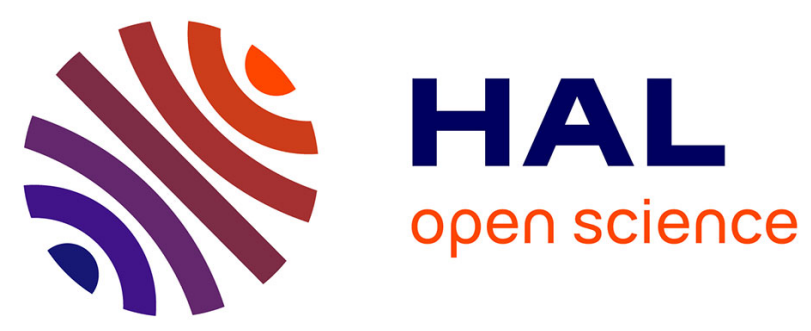

\title{
Wall shear stress and endothelial cells dysfunction in the context of abdominal aortic aneurysms
}

Zuzana Macek Jilkova, Valérie Deplano, Claude Verdier, Mamadou Toungara, Christian Geindreau, Alain Duperray

\section{- To cite this version:}

Zuzana Macek Jilkova, Valérie Deplano, Claude Verdier, Mamadou Toungara, Christian Geindreau, et al.. Wall shear stress and endothelial cells dysfunction in the context of abdominal aortic aneurysms. Computer Methods in Biomechanics and Biomedical Engineering, 2013, 16 (supp1), pp.27-29. hal00853100

\section{HAL Id: hal-00853100 \\ https://hal.science/hal-00853100}

Submitted on 21 Aug 2013

HAL is a multi-disciplinary open access archive for the deposit and dissemination of scientific research documents, whether they are published or not. The documents may come from teaching and research institutions in France or abroad, or from public or private research centers.
L'archive ouverte pluridisciplinaire HAL, est destinée au dépôt et à la diffusion de documents scientifiques de niveau recherche, publiés ou non, émanant des établissements d'enseignement et de recherche français ou étrangers, des laboratoires publics ou privés. 


\title{
Wall shear stress and endothelial cells dysfunction in the context of abdominal aortic aneurysms
}

\author{
Z. Macek Jilkova†, V. Deplano ${ }^{\#}$, C. Verdier†, M. Toungara ${ }^{\S}$, C. Geindreau ${ }^{\S}$ and A. Duperray $\dagger^{*}$ \\ $\dagger$ INSERM, IAB, U823, Grenoble; † CNRS, LIPhy, UMR5588, Grenoble, ${ }^{\S}$ Lab 3SR UMR5521 CNRS UJF G-INP, \\ Grenoble; ${ }^{\sharp}$ CNRS, IRPHE, UMR7342,13384 Marseille
}

Keywords: wall shear stress, abdominal aortic aneurysm, endothelial cells, mechanotransduction

\section{Introduction}

The formation of aneurysm of abdominal aorta (AAA), is a multi-factorial and predominantly degenerative process that results from a complex interplay between biological processes in the arterial wall and the hemodynamic stimuli on the wall, i.e. wall shear stresses (WSS) and elongations of the wall directly applied on vascular endothelial cells (EC) partly regulate the arterial wall remodelling (Golledge et al, 2006, Humphrey et al 2012). In the case of AAA, these mechanical stimuli strongly vary in space and time, leading to strong spatio-temporal gradients (Figure 1). The effect of these abnormal mechanical stimuli leads to EC dysfunction. This phenomenon plays a significant role in AAA pathology, where damage of EC, associated with changes of endothelial permeability and increased local inflammation, appears to be the initial step of AAA formation and expansion. In the last two decades, many in vitro studies have been performed in order to characterize the influence of WSS (Chiu and Chien 2011) on the EC biological response. Recently the coupling between elongation and WSS has been also investigated. However, these stimuli remain usually very far from the ones encountered in AAA during its expansion, and do not allow to clearly understand the links between blood WSS - AAA wall stress and elongations - EC dysfunction. Within this context, new experiments need to be developed in order to reproduce such pathological loadings on EC. In the present study, we present results concerning the influence of WSS only on EC dysfunction in a parallel plate flow channel. A preliminary set of in vitro experiments have been performed applying three different values of WSS, which represent the WSS over a cardiac cycle at three different locations in a typical AAA geometry. These tests will be then used as reference in order to measure the influence of the pathological spatio-temporal gradients of WSS.

\section{Methods}

Primary human umbilical vein EC (HUVEC) were plated on fibronectin-coated slides $(10 \mu \mathrm{g} / \mathrm{mL})$ and confluent monolayers were exposed to flow in a closed circulating system using a peristaltic pump for $18 \mathrm{~h}$ or incubated under static conditions, in both cases with $5 \% \mathrm{CO}_{2}$ at $37{ }^{\circ} \mathrm{C}$. For flow experiments, we used a parallel plate flow chamber, as described previously (Chotard-Ghodsnia et al., 2002). Constant shear stress applied on cells varies from $0.04 \mathrm{~Pa}$ to $3.7 \mathrm{~Pa}\left(0.4\right.$ to $\left.37 \mathrm{dynes} / \mathrm{cm}^{2}\right)$, which corresponds to levels of WSS during enlargement of AAA (Salsac et al., 2004). Cell alignment and shape were investigated on digitized images, analyzed with MetaMorph software $(n \geqslant 500 /$ per experiment). Cell orientation (alignment) was determined as an angle between the long axis of the cell and the chosen direction $\left(0^{\circ}\right.$ indicated perfect alignment with respect to the flow direction while a value of $45^{\circ}$ indicated no alignment). Elliptical form factor, the ratio of the cell's breadth to its length, determined the level of cells elongation (1 indicated circle i.e. no elongation). EC dysfunction was determined by immunocytochemistry, confocal fluorescence microscopy and flow cytometry.

Data were analyzed using SigmaStat statistical software. One-way ANOVA followed by multiple comparisons with Holm-Sidak test was used. For direct comparisons, an unpaired Student's t test was used. Values are presented as means \pm SE. Comparisons were judged to be significant at $p<$ 0.05 .

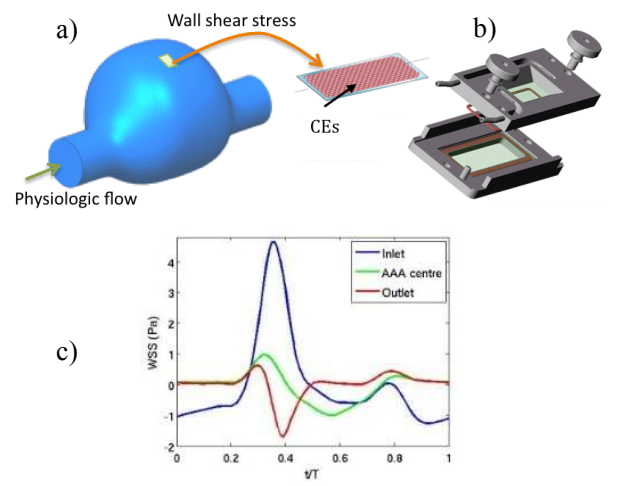

Figure 1 a) AAA macro scale model. b) Micro scale study. c) Wall shear stress during the cardiac cycle at different locations of AAA.

\section{Results and Discussion}

The orientation and elongation of EC (figure $2 \mathrm{a}$ et b) were analysed (Table 1). Compared to static state, characterized by random orientation, we observed that HUVEC partially aligned in direction of flow after $18 \mathrm{~h}$ of exposure to shear stress of 2.0 $\mathrm{Pa}$. The alignment was even more pronounced

\footnotetext{
* Email: alain.duperray@ujf-grenoble.fr
} 
in response to very high shear stress of $3.7 \mathrm{~Pa}$. Confluent EC are known to be polygonal under static culture conditions, but become elongated in response to shear stress (Dewey et al., 1981). In our study, the elongation was significantly elevated in HUVEC already after exposure to shear stress of $0.04 \mathrm{~Pa}$ and further increased with higher magnitudes of shear stresses, clearly demonstrating the gradual elongation of HUVEC.

Then we investigated the response of cytoskeletal organization to the shear stress stimuli. After $18 \mathrm{~h}$ of $2.0 \mathrm{~Pa}$ shear stress, HUVEC displayed long, well-organized, parallel actin stress fibers largely aligned with the flow direction in the central regions of the cells and linear distribution of vascular endothelial (VE)-cadherin, adhesion molecule located at junctions between EC, was similar to immunostaining of cells-junctions in arteries in vivo (Noria et al., 2004).

The effect of shear stress on surface expression of various adhesion molecules (i.e., ICAM-1, VCAM1, and E-selectin) was determined using flow cytometry analysis. Application of flow for $18 \mathrm{~h}$ significantly increased ICAM-1 surface expression in case of $0.04 \mathrm{~Pa}$ but not in case of higher levels of WSS (Table 1). This is consistent with general statement that inflammation develops mainly in areas of low shear stress, while areas exposed to a higher shear stress are protected (Cecchi et al. 2011). Surface expression of neither VCAM-1 nor E-selectin was changed. To investigate the fibronectin-integrin-cytoskeleton linkage, we analysed the regulation of $\beta 1$ Integrin by shear stress. We observed strongly induced surface expression of $\beta 1$ Integrin by flow (Table 1) suggesting the important role of this protein in mechanotransduction pathways signalling.

\begin{tabular}{|l|c|c|c|c|}
\hline & static & $0.04 \mathrm{~Pa}$ & $2.0 \mathrm{~Pa}$ & $3.7 \mathrm{~Pa}$ \\
\hline Orientation & $44 \pm 2$ & $42 \pm 2$ & $29 \pm 3^{*}$ & $17 \pm 1^{*}$ \\
\hline Elongation & $2.2 \pm 0.1$ & $2.7 \pm 0.1^{*}$ & $3.2 \pm 0.3^{*}$ & $3.7 \pm 0.2^{*}$ \\
\hline ICAM-1 & $1 \pm 0.5$ & $2.7 \pm 0.7^{*}$ & $1.9 \pm 0.5$ & $1.5 \pm 0.2$ \\
\hline$\beta 1$ Integrin & $1 \pm 0.2$ & $3.6 \pm 1.1^{*}$ & $1.9 \pm 0.1^{*}$ & $1.8 \pm 0.1^{*}$ \\
\hline
\end{tabular}

Table 1 Shear stress-induced changes in EC orientation $\left(^{\circ}\right)$ and elongation and in surface expression of ICAM- 1 and $\beta 1$ Integrin. Data are means $\pm \mathrm{SE}(\mathrm{n}=5)$. *Significantly different from static condition.

\section{Conclusions and perspectives}

Our preliminary results confirm that high levels of WSS are not apparently, in themselves, the cause of the AAA pathology, suggesting that rather WSSG plays a key role in this disease. The directly study of the spatio-temporal WSSG remains a challenge. For that purpose, we recentlty developed PDMS model of AAA and EC were placed and cultured inside of models to obtain confluent monolayer. We tested the maintaining of cells monolayers after exposure to WSS (2.0 Pa in "healthy" part of aorta). Cells, exposed to flow in a closed circulating system using peristaltic pump for $8 \mathrm{~h}$, were fixed and observed by confocal microscope. As shown in Figure 2c, the cell monolayer was maintained even in area of maximum AAA radius. These original experimental set-up offer interesting perpectives in order to study spartio-temporal gradient of WSS in AAA.
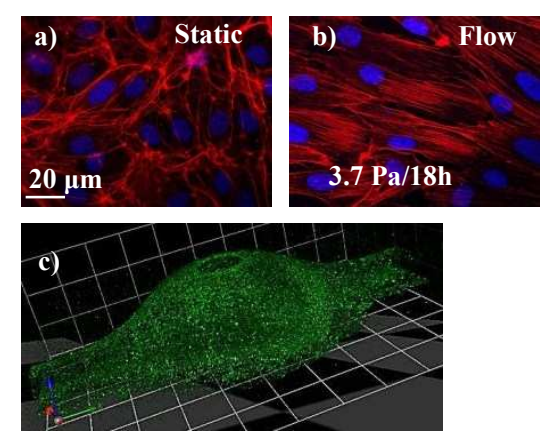

Figure 2a, b) Actin (Phalloidin Texas Red) and Cells' nuclei (Hoechst). a) HUVEC without flow: random and short filaments at cell periphery. b) HUVEC with flow: Long and parallel stress fibers in central regions. c) Confocal microscopy of AAA model made of PDMS with EC covering the inside walls.

\section{Acknowledgments}

The authors gratefully acknowledge the University Joseph Fourier for financial support.

\section{References}

Cecchi E, Giglioli C, Valente S, Lazzeri C, Gensini GF, Abbate R, Mannini L, 2011.Role of hemodynamic shear stress in cardiovascular disease. Atherosclerosis. 214(2):249-56

Chiu JJ and Chien S. Effects of disturbed flow on vascular endothelium: pathophysiological basis and clinical perspectives. Physiol Rev, 91, 327387 (2011)

Chotard-Ghodsnia ., Drochon A, Grebe R, 2002. A new flow chamber for the study of shear stress and transmural pressure upon cells adhering to a porous biomaterial. J Biomech Eng, Apr, 124(2), 258-261.

Dewey CF Jr, Bussolari SR, Gimbrone MA Jr, Davies PF. 1981. The dynamic response of vascular endothelial cells to fluid shear stress. J Biomech Eng. 103:177-85

Golledge J, Muller J, Daugherty A, Norman P. 2006. Abdominal aortic aneurysm: pathogenesis and implications for management. Arterioscler Thromb Vasc Biol. 26(12):2605-13

Humphrey JD, Holzapfel GA. 2012. Mechanics, mechanobiology, and modeling of human abdominal aorta and aneurysms. J Biomech. 45:805-14

Noria S, Xu F, McCue S, Jones M, Gotlieb AI, Langille BL, 2004. Assembly and reorientation of stress fibers drives morphological changes to endothelial cells exposed to shear stress. Am J Pathol. 164:1211-23

Salsac AV, Sparks SR, Lasheras JC. 2004. Hemodynamic changes occurring during the progressive enlargement of abdominal aortic aneurysms. Ann Vasc Surg. 18(1):14-21 